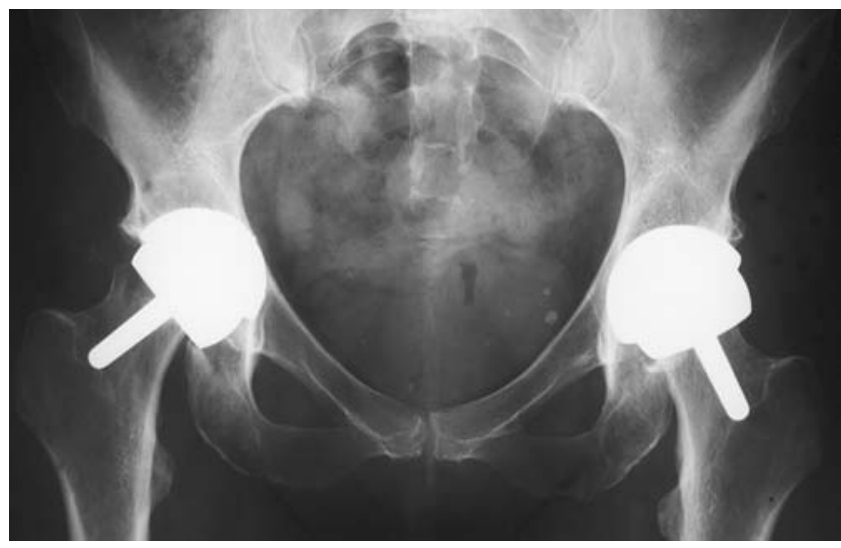

Fig. 3

Radiograph showing varus tilting of the femoral component and a fracture of the femoral neck two weeks after the operation.

Score $^{5}$ of 14 for the right and 12 for the left hip confirmed excellent function. Radiographs at 15 months showed further remodelling.

\section{Discussion}

Although there have been few published results of the Birmingham hip resurfacing technique, fracture of the femoral neck, particularly if there is notching of the bone and varus alignment of the femoral component, is a complication which has been described following previous similar techniques. ${ }^{6}$

There have been no previous reports of the conservative management of this complication of hip resurfacing. In patients who sustain a minimally displaced peri-prosthetic femoral fracture in the early post-operative period after hip resurfacing, it would seem reasonable to try a period of conservative management before considering further surgery.

No benefits in any form have been received or will be received from a commercial party related directly or indirectly to the subject of this article.

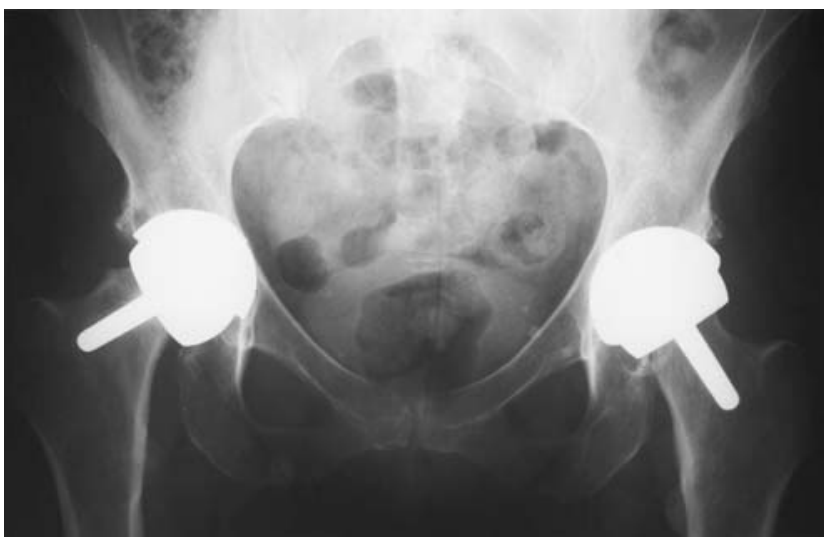

Fig. 4

Radiographic follow-up at nine months showing union and remodelling of the fracture.

\section{References}

1. Freeman MAR, Cameron HU, Brown GC. Cemented double-cup arthroplasty of the hip: a 5-year experience with the ICLH prosthesis. Clin Orthop 1978;134:45-52.

2. Bell RS, Schatzker J, Fornasier VL, Goodman SB. A study of implant failure in the Wagner resurfacing arthroplasty. J Bone Joint Surg [Am] 1985;67-A:1165-75.

3. Wagner M, Wagner H. Preliminary results of uncemented metal on metal stemmed and resurfacing hip replacement arthroplasty. Clin $\mathrm{Or}$ thop 1996;329S:S78-S88.

4. McMinn D, Treacy R, Lin K, Pynsent P. Metal on metal surface replacement of the hip. Clin Orthop 1996;329S:S89-S98.

5. Dawson J, Fitzpatrick R, Carr A, Murray D. Questionnaire on the perceptions of patients about total hip replacment. J Bone Joint Surg [Br] 1996;78-B:185-90.

6. Freeman MAR. The complications of double-cup replacement of the hip. In: Ling RSM, ed. Complications of total hip replacement. Edinburgh, Scotland: Churchill Livingstone, 1954;172-200.

\title{
INTRAPELVIC DISLOCATION OF THE HEAD OF FEMUR THROUGH THE OBTURATOR FORAMEN ASSOCIATED WITH IPSILATERAL FRACTURE FEMUR
}

\author{
A. W. Farag, K. A. Shohayeb \\ From Cairo University, Cairo, Egypt
}

$\mathbf{W}$ e describe a case of traumatic anterior dislocation of the hip in a 14-year-old boy with associated intrapelvic displacement of the femoral head and ipsilateral fractures of the shaft of the femur and greater trochanter. There was a

A. W. Farag, MD, MSc, Associate Professor of Orthopaedic Surgery

K. A. Shohayeb, MD, MSc, Lecturer in Orthopaedic Surgery

Orthopaedic Department, Misr International Hospital, 12 El Soraya St.,

Vinni Square, Dokki, Cairo, Egypt.

Correspondence should be sent to Dr A. W. Farag.

C2003 British Editorial Society of Bone and Joint Surgery doi:10.1302/0301-620X.85B7.13712 \$2.00 delay in presentation of eight days. At operation the femoral head was reduced into the acetabulum after enlarging the obturator foramen by performing an osteotomy of the superior pubic ramus.

J Bone Joint Surg [Br] 2003;85-B:1056-8.

Received 29 July 2002; Accepted after revision 26 March 2003

Traumatic dislocations of the hip have been classified as anterior, posterior and fracture dislocations. ${ }^{1}$ Anterior dislocations have been further classified as: inferior, luxatio erecta of the hip, supe- 


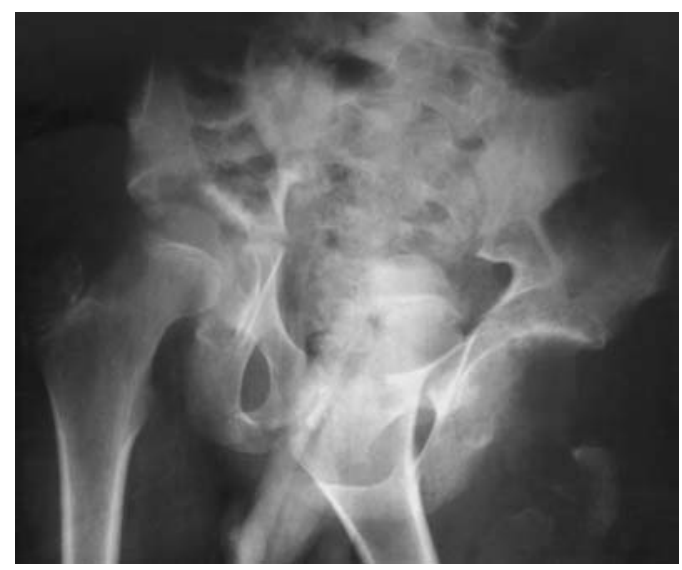

Fig. 1a

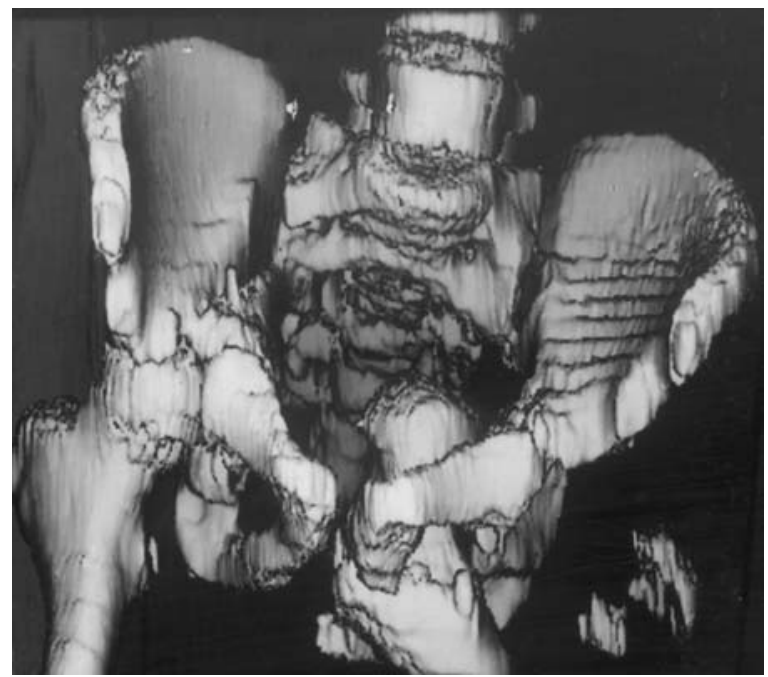

Fig. 1c

rior, pubic and obturator. ${ }^{2-4}$ To our knowledge, an associated intrapelvic dislocation of the femoral head has not been previously described.

\section{Case report}

A 14-year-old boy was involved in a road traffic accident in a remote rural area and was transferred to the nearest hospital. His vital signs were normal but there was suprapubic tenderness and haematuria. There was shortening of the left lower limb with crepitus and deformity of the thigh, but without neurovascular compromise. Radiographs revealed intrapelvic dislocation of the left femoral head, an ipsilateral femoral fracture and avulsion of the greater trochanter. He underwent emergency laparotomy and an extraperitoneal rupture of the bladder was repaired. An external fixator was applied to the fractured femur. Closed reduction of the dislocated femoral head was attempted and failed.

Eight days later, he was transferred to our hospital. His general condition was stable. Further radiographs, three-dimensional CT scans (Fig. 1) and angiography were performed and showed an associated fracture of the left inferior pubic ramus with no damage to the external iliac or femoral arteries.

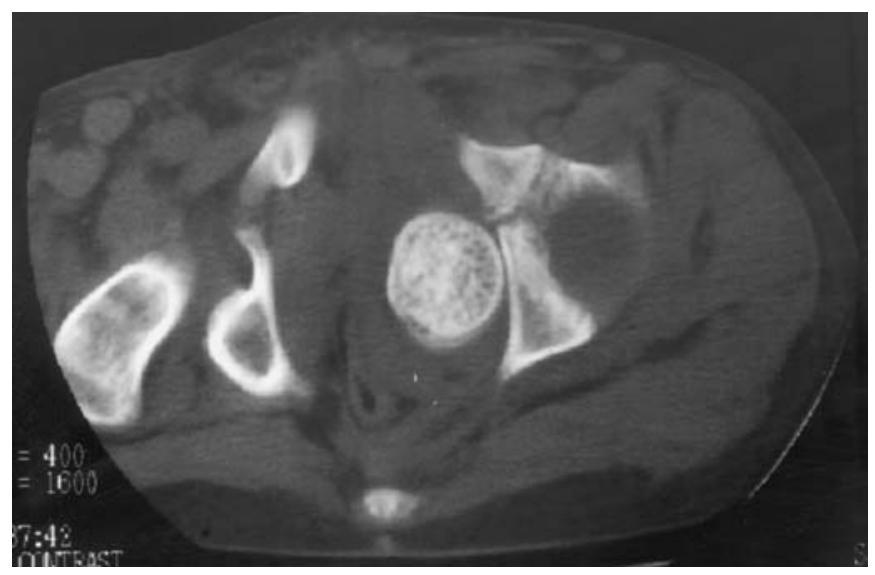

Fig. 1b

Radiographs showing a) intrapelvic dislocation of the left femoral head, b) CT scan and c) 3-D CT reconstruction.

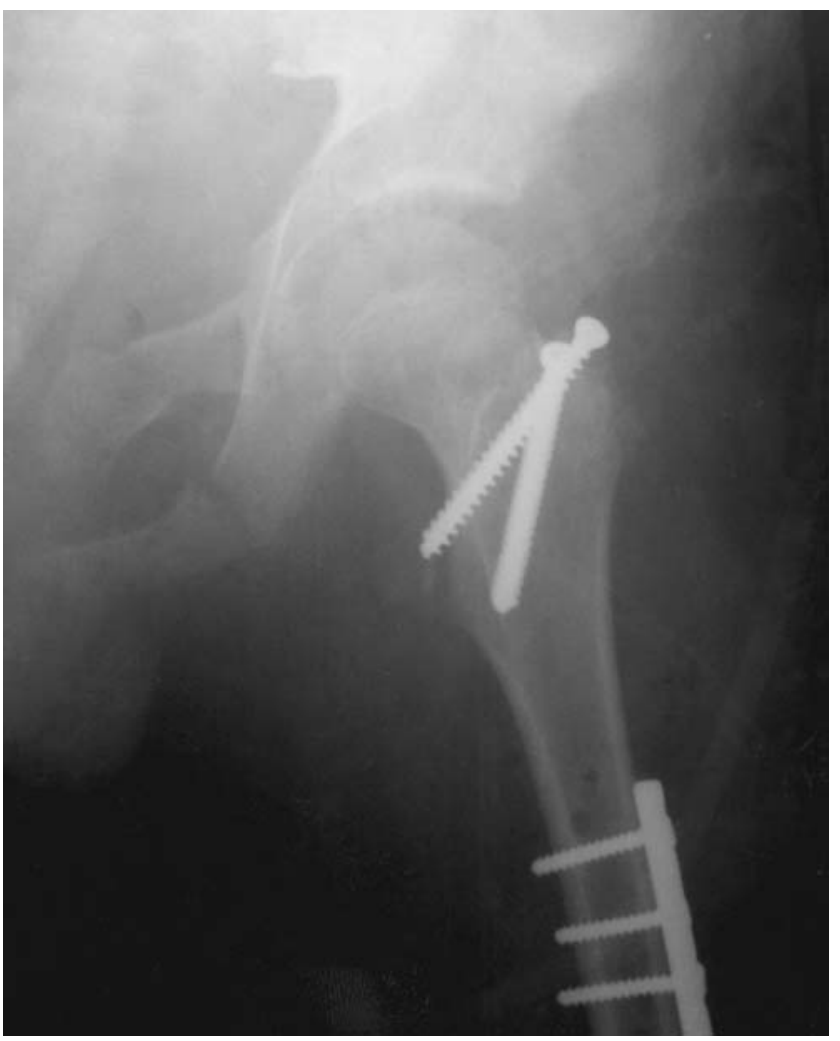

Fig. 2

Postoperative radiograph showing reduction of the dislocation and fixation of the femoral shaft and greater trochanteric fractures. 
At surgery the hip was approached through an ilioinguinal incision and the proximal pins of the femoral external fixator were used to manipulate the proximal femur. An osteotomy of the superior pubic ramus was performed in order to enlarge the obturator foramen and allow reduction of the femoral head. The hip seemed grossly stable. The external fixator was removed and through a lateral approach the femoral fracture was internally fixed by means of a dynamic compression plate, and the fractured trochanter fixed with two cancellous screws (Fig. 2). Postoperatively, skin traction was maintained for three weeks.

At the latest follow-up (one year postoperatively), radiographs showed grade II avascular necrosis (AVN) of the femoral head. He had a reduced range of movement and a mild limp.

\section{Discussion}

Approximately $11 \%$ of all hip dislocations are anterior, and of these, approximately $70 \%$ are inferior. ${ }^{4,5}$ Bilateral obturator dislocation of the hip has been described with the femoral heads lying anterior to the obturator membrane ${ }^{6}$ Central dislocation involves a fracture of the acetabulum. ${ }^{5}$ Dislocation of the hip and ipsilateral femoral fracture $e^{7-9}$ and associated avulsion of the greater trochanter have been reported. ${ }^{10}$

The usual mechanism of injury is abduction, flexion and external rotation of the hip. ${ }^{5,6,10}$ However, to our knowledge, the type of dislocation in this case report has not previously been described. The head of the femur was lying within the pelvic cavity having passed through the obturator foramen by means of an associated fracture of the inferior pubic ramus. A three-dimensional CT scan and angiography were required to assess the injury fully.

Although several extended approaches to the hip have been described, ${ }^{11-13}$ we chose to combine the ilioinguinal approach with a lateral approach to the femur in order to allow access to the hip and fixation of the ipsilateral femoral and trochanteric fractures. Extended approaches have high postoperative complication rates and require long periods of rehabilitation. ${ }^{11}$ The ilioinguinal approach allowed osteotomy of the superior pubic ramus which was required to complete the reduction of the hip.

Although the incidence of AVN of the femoral head is reported to be less after anterior than posterior dislocation of the hip, ${ }^{3,14,15}$ we believe that in our case, the development of AVN was almost inevitable. The extensive soft-tissue damage and the delay of eight days before reduction was performed would both have caused compromise to the blood supply to the femoral head.

No benefits in any form have been received or will be received from a commercial party related directly to the subject of this article. No funds were received in support of this study.

\section{References}

1. Goddard NJ. Classification of traumatic hip dislocation. Clin Orthop 2000;377:11-4

2. Beauchesne R, Kruse R, Stanton RP. Inferior dislocation (luxatio erecta) of the hip. Orthopaedics 1994;17:72-4.

3. Epstein HC. Traumatic dislocations of the hip. Clin Orthop 1973; 92:116-42.

4. Erb RE, Steele JR, Nance EP, Edwards JR. Spectrum of plain film and CT findings. AJR Am J Roentgenol 1995;165:1215-9.

5. Phillips AM, Konchwalla A. The pathologic features and mechanism of traumatic dislocation of the hip. Clin Orthop 2000;377:7-11.

6. Endo S, Hoshi S, Takayama H, Kam E. Traumatic bilateral obturator dislocation of the hip joint. Injury 1991;22:232-3.

7. Helel B, Skevis X. Unrecognised dislocation of the hip in fractures of the femoral shaft. J Bone Joint Surg [Br] 1967;49-B:293-300.

8. Mosheiff R, Segal D, Wollstein R, Sagiv S, Liebergall M. Midshaft femoral fracture, concomitant ipsilateral hip joint injury and disruption of the knee extensor mechanism: a unique triad of dashboard injury. Am J Orthop 1998;27:465-73.

9. Taylor MT, Banerjee B, Alpar EK. Injuries associated with a fractured shaft of the femur. Injury 1994;25:185-7.

10. Maruoka A, Naka N, Saito M, Toma Y. Pubic type dislocation of the hip combined with fracture of the ipsilateral greater trochanter: a case report. Arch Orthop Trauma Surg 1993;112:304-16.

11. Bauer GJ, Sarkar MR. Injury classification and surgical approach in hip dislocations and fractures. Orthopade 1997;26:304-16.

12. Judet R, Judet J, Letournel E. Fractures of the acetabulum: classification and surgical approach for open reduction: a preliminary report. J Bone Joint Surg [Am] 1964;46-A:1615-46.

13. Matta JM. Dislocations of the hip and fractures of the acetabulum. In McCollister Evarts C, ed. Surgery of the musculoskeletal system. 2nd ed, Vol. 3. New York: Churchill Livingstone, 1990.

14. Brav EA. Traumatic dislocation of the hip: army experience and results over a twelve-year period. J Bone Joint Surg [Am] 1962;44-A: 1115-21.

15. Rodriguez-Merchan EC. Osteonecrosis of the femoral head after traumatic hip dislocation in the adult. Clin Orthop 2000;377:68-77. 